\title{
Effect of Fins on the Transition to Oscillating Laminar Natural Convection in an Enclosure
}

\author{
Emel Evren Selamet and Ahmet Selamet \\ Ohio State University, Mechanical and Aerospace Engineering, USA
}

\begin{abstract}
Flow characteristics and evolution of heat transfer are investigated numerically within a differentially heated square cavity in the presence of thin fins which are either insulated or highly conductive and at the base wall temperature. The transition from steady-state to oscillatory and chaotic convection is observed at certain Rayleigh numbers with varying lengths of fins positioned at different locations.
\end{abstract}

\section{Introduction}

Modification of heat transfer in cavities with fins attached to the wall(s) has been subject of several investigations. Depending on the application, either the suppression or the enhancement of heat transfer such as solar collectors and electronic cooling by natural convection may be desirable. This goal guides the design through choosing the relevant parameters appropriately. Winters [1] and Sathiyamoorthy and Chamkha [2], for example, considered a vertical divider in the middle of bottom wall; Faces [3] studied two fins on the hot, one on the cold wall in a tall cavity; Nag, et al. [4], Shi and Khodadadi [5], and Bilgen [6] investigated a thin fin on the hot wall; and Nada [7] examined multiple fins on the hot wall of a narrow enclosure both horizontal and vertical.

The present work is a numerical investigation of heat transfer and fluid flow characteristics in a square enclosure which incorporates two fins of varying lengths and locations on hot and cold vertical walls. Transition from steady-state to oscillatory and chaotic convection occurring at certain Rayleigh numbers is examined as such geometric parameters are varied.

The definition and formulation of the problem is next, followed by the validation of the code, discussion of results from selected configurations, and concluding remarks.

\section{Problem definition}

Similar to other natural convection flow models, the present study considers a square cavity. The horizontal walls are thermally insulated and the vertical walls are kept at temperatures of $\mathrm{T}_{h}$ (hot left wall) and $\mathrm{T}_{\mathrm{c}}$ (cold right wall), respectively. In terms of the following dimensionless variables $x=x^{*} / L, \quad y=y^{*} / L ; \quad u=u^{*} L / \alpha$, $v=v^{*} L / \alpha ; t=t^{*} \alpha / L^{2} ; p=p^{*} L^{2} /\left(\rho \alpha^{2}\right) ; \Theta=\left(T-T_{c}\right) /\left(T_{h}-T_{c}\right)$ where $x^{*}, y^{*}$ are the coordinates; $u^{*}, v^{*}$ the velocities; $t^{*}$ the time; $p^{*}$ the pressure; $T$ the temperature; $L$ the width of the enclosure, the governing equations for mass, $x$ - and y-momentum, and energy may be written for buoyancydriven incompressible fluids as

$$
\begin{gathered}
\frac{\partial u}{\partial x}+\frac{\partial v}{\partial y}=0 \\
\frac{\partial u}{\partial t}+\frac{\partial u^{2}}{\partial x}+\frac{\partial u v}{\partial y}=-\frac{\partial p}{\partial x}+\operatorname{Pr} \nabla^{2} u \\
\frac{\partial v}{\partial t}+\frac{\partial u v}{\partial x}+\frac{\partial v^{2}}{\partial y}=-\frac{\partial p}{\partial y}+\operatorname{Pr} \nabla^{2} v+\operatorname{Ra} \operatorname{Pr} \Theta \\
\frac{\partial \Theta}{\partial t}+\frac{\partial u \Theta}{\partial x}+\frac{\partial v \Theta}{\partial y}=\nabla^{2} \Theta
\end{gathered}
$$

where $\nabla^{2}$ the two-dimensional Laplacian; $\operatorname{Pr}=v / \alpha$, the Prandtl number; $\mathrm{Ra}=\mathrm{g} \beta \Delta \mathrm{TL}^{3} / v \alpha$, the Rayleigh number which accounts for the coupling between energy and momentum balances, $\mathrm{g}$ being the gravitational acceleration, $\beta$ the coefficient of thermal expansion of the fluid, $\Delta \mathrm{T}$ the temperature difference between left and right boundaries; $v$ the kinematic viscosity; and $\alpha$ the thermal diffusivity. Boussinesq approximation, which treats density as a constant in all equations except the gravitational force term in the momentum equation, is used. Even though the computations are performed by using primitive variables, flow field results are presented in terms of the stream function $\Psi(\mathrm{u}=\partial \Psi / \partial \mathrm{y}, v=-\partial \Psi / \partial \mathrm{x})$. No slip boundary conditions are imposed on all walls and fins. The governing equations with primitive variables are solved on a staggered grid by applying the Godunov scheme to convective terms and centered finite difference to diffusive terms. Details of the method are explained in the earlier work of the lead author [8].

The fluid is assumed to be air with $\operatorname{Pr}=0.71$. In the present configuration, two horizontal fins are attached to 
both vertical (hot and cold) walls. Two cases are then considered in the study:

1. Fins are thermally insulated,

2. Fins are highly conductive, thus isothermal at the base wall temperature.

\subsection{Validation for an enclosure with single fin}

The results from the present predictions are first compared with those from the earlier work of Shi and Khodadadi [5] who studied natural convection in a differentially heated square cavity with a single thin fin mounted on the hot wall. They considered the fin at the base wall temperature (highly conductive fin) and obtained the solution with steady-state governing equations. They also indicated that the solution didn't converge due to not retaining the unsteady terms in some cases at $\mathrm{Ra}=10^{6}$ and $10^{7}$. Although a steady solution exists at those $\mathrm{Ra}$ in the absence of fin, it becomes unsteady with the introduction of fin depending on the fin's length and location. A representative case is considered here with a fin located in the middle of vertical wall. Fig. 1 compares at $\mathrm{Ra}=10^{5}$ the results from the present study with [5] in terms of absolute maximum value of stream function field $\Psi_{\max }$ - a measure of intensity of natural convection - for a fin length of $\mathrm{l}_{\mathrm{f}}=0.5$ and as a function of fin location $\mathrm{s}$. Here, both $1_{\mathrm{f}}$ and $\mathrm{s}$ are nondimensionalized with respect to $L$, with s representing the distance from top of the enclosure. The agreement between two studies is excellent. For this case, the solution is steady regardless of the fin location. For higher Ra, however, a similar comparison cannot be made since $\Psi_{\max }$ oscillates, and so does the Nusselt number $(\mathrm{Nu})$ - the ratio of heat transferred by convection to that of conduction, or, alternatively the dimensionless temperature gradient. The resulting unsteady nature of the thermal field is examined in the present study in terms of the evolution of $\mathrm{Nu}$ at

$\mathrm{Ra}=10^{7}$. Fig. 2 depicts $\mathrm{Nu}$ on the left side of cavity, without fin and with fins of different lengths located at $\mathrm{s}=0.5$. Nu variation as a function of time shown in Fig. $2 \mathrm{a}$ is calculated only at the hot wall vs. hot wall plus fin in Fig. 2b which yields the total heat transfer. Bilgen [6] studied this problem numerically with different fin conductivities after introducing a ratio of conductivity of fin to fluid and varying this ratio between 0 (case 1 in the present work) and 60. Steady solutions were obtained from unsteady-state equations by using commercial code SIMPLER, though no referral was made to unsteadiness of solutions. She calculated $\mathrm{Nu}$ at the wall only, excluded heat transfer from the fin, and indicated that $\mathrm{Nu}$ decreased as a function of fin length as observed (on the mean) in Fig. 2a. Fig. 2 shows regular sinusoidal oscillations for $\mathrm{l}_{\mathrm{f}}=0.1,0.2$, and 0.35 ; non-sinusoidal but regular for $\mathrm{l}_{\mathrm{f}}=0.5$; and non-sinusoidal and irregular behavior for $\mathrm{l}_{\mathrm{f}}=0.7$. In Fig. $2 \mathrm{~b}$ the frequency of oscillations decreases, while the amplitude increases with increasing fin length for $0.1 \leq 1_{\mathrm{f}} \leq 0.35$. $\mathrm{Nu}$ is smaller than that of without fin for $\mathrm{l}_{\mathrm{f}} \leq 0.1$ at this fin location. At lower $\mathrm{Ra}\left(=10^{6}\right)$, this is true for $\mathrm{l}_{\mathrm{f}} \leq 0.2$ with the same parameters of fin and the solution is steady for $1_{\mathrm{f}}<0.35$ and decaying oscillations are observed for $\mathrm{l}_{\mathrm{f}}=0.35$ and 0.5 .

Flow and temperature fields are visualized in Fig. 3 for $\mathrm{Ra}=10^{7}$ in terms of streamlines and isotherms at three fin lengths chosen from Fig. 2: $1_{\mathrm{f}}=0.1(\mathrm{a}, \mathrm{d}), \mathrm{l}_{\mathrm{f}}=0.35(\mathrm{~b}, \mathrm{e})$, and $\mathrm{l}_{\mathrm{f}}=0.5(\mathrm{c}, \mathrm{f})$. One or two counter clockwise rotating vortices are observed above the fin in the separation region with their strength and size depending on the fin length. It is interesting to examine the flow field at different times of the cycle for oscillating flows. For example, Fig. 4 shows the streamlines at four different times each separated by an interval of 0.0008 which is approximately a quarter of the period of irregular oscillations for $\mathrm{l}_{\mathrm{f}}=0.7$ at $\mathrm{Ra}=10^{7}$. The evolution in this sequence suggests that the unsteadiness is essentially caused by the separation region. Two small vortices are observed in that region at $\mathrm{t}=.1208$, then one of them gets stronger affecting the flow field on top of it, and making the weaker one disappear near the end of the cycle

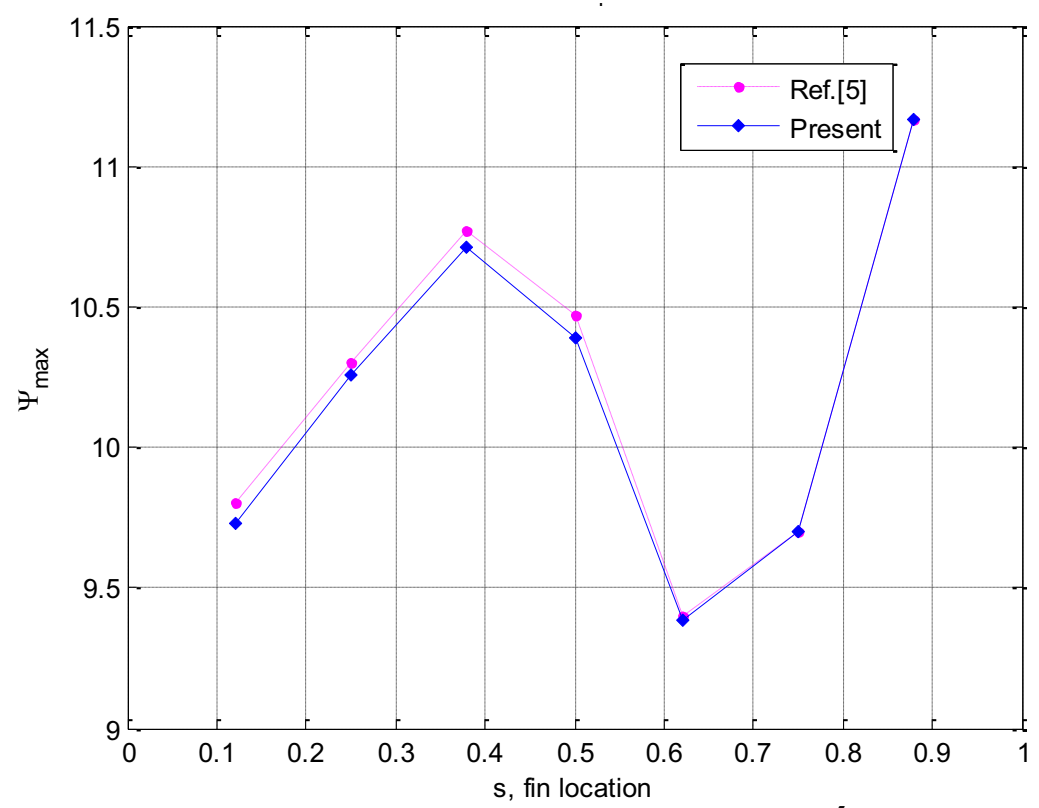

Figure 1. Variation of absolute value of $\Psi \max$ with the location (s) of fin at $\mathrm{Ra}=10^{5}$ for a fin length of $\mathrm{l}_{\mathrm{f}}=0.5$. 

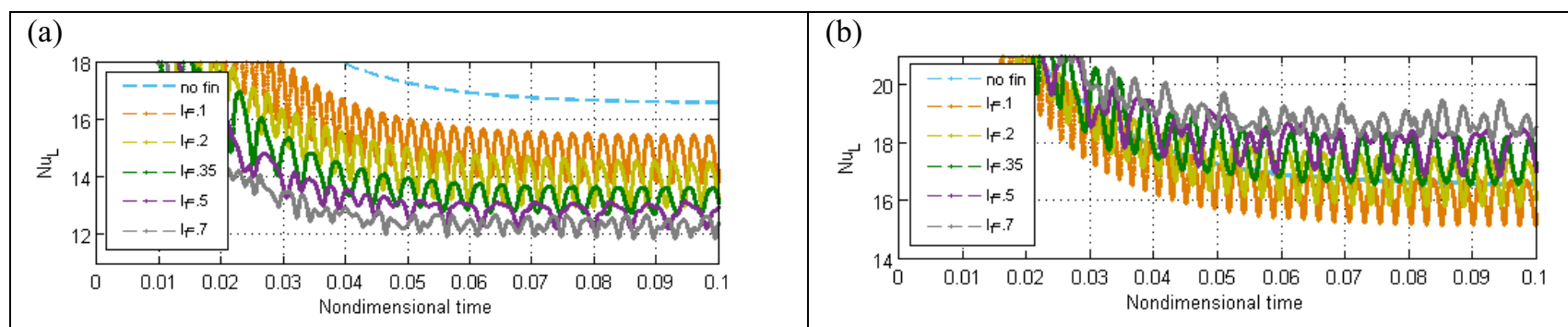

Figure 2. Evolution of $\mathrm{Nu}_{\mathrm{L}}$, (a) calculated only at the wall, (b) calculated at the wall + fin for $\mathrm{s}=0.5, \mathrm{l}_{\mathrm{f}}=0,0.1,0.2,0.35$, 0.5 and 0.7 for $\mathrm{Ra}=10^{7}$.

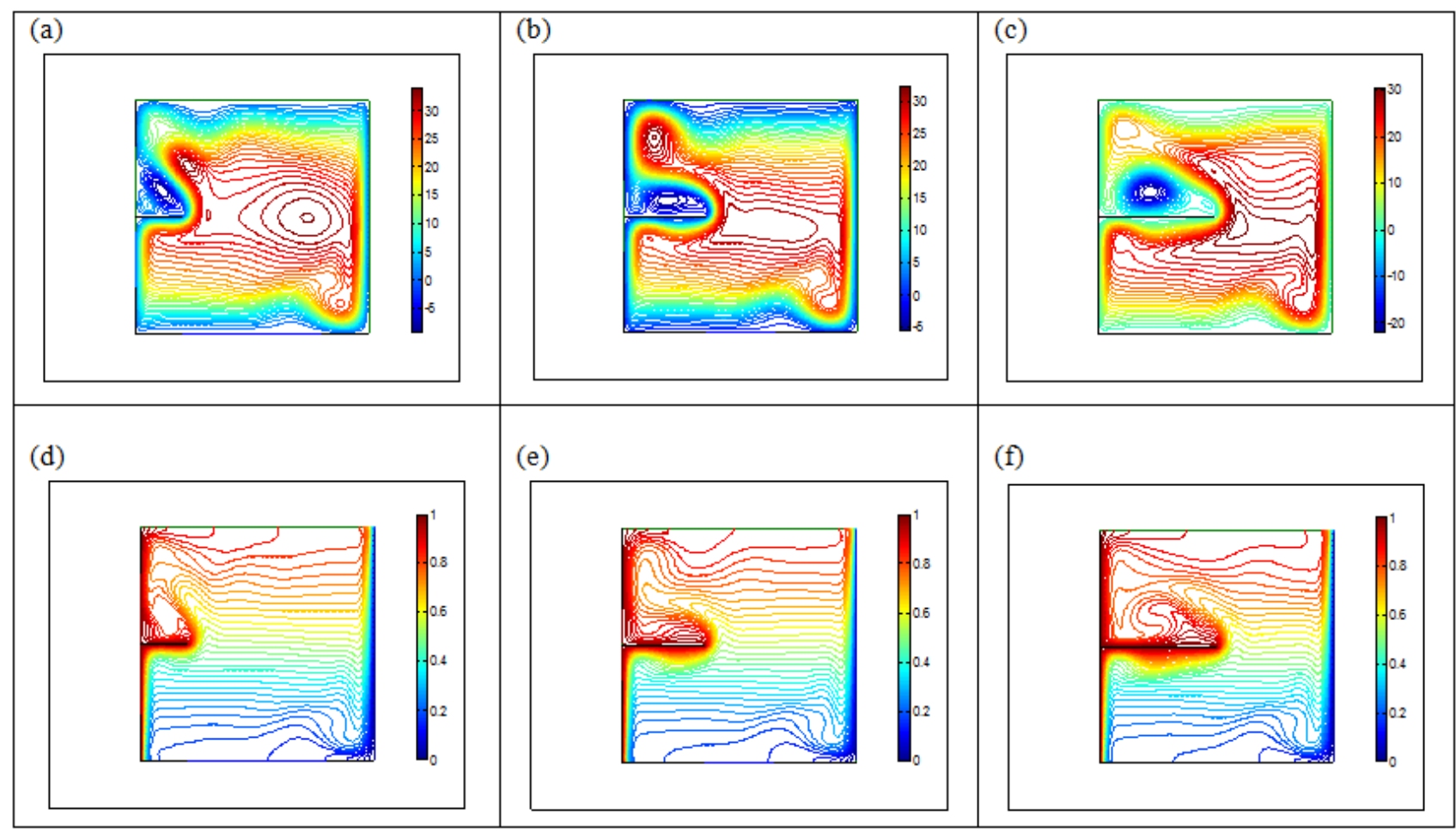

Figure 3. Streamlines and isotherms for $\mathrm{l}_{\mathrm{f}}=0.1(\mathrm{a}, \mathrm{d}), \mathrm{l}_{\mathrm{f}}=0.35(\mathrm{~b}, \mathrm{e})$ and $\mathrm{l}_{\mathrm{f}}=0.5(\mathrm{c}, \mathrm{f}$,$) , respectively for \mathrm{Ra}=10^{7}$ at $\mathrm{t}=0.12$.

$t=0.1208$

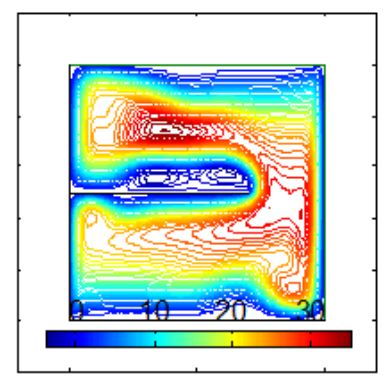

$t=0.1224$

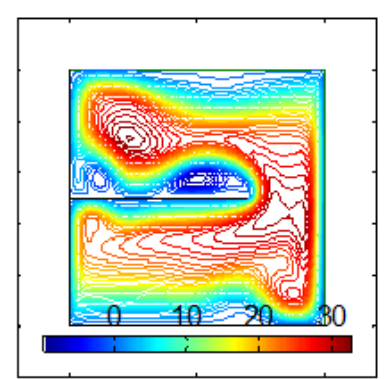

$t=0.1216$

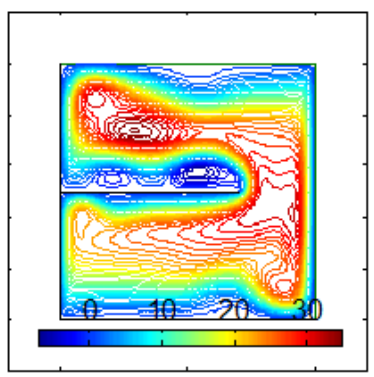

$\mathrm{t}=0.1232$

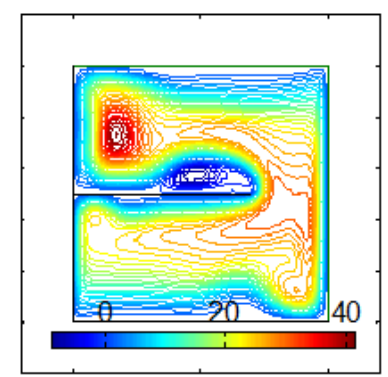

Figure 4. Streamlines at different times for $\mathrm{l}_{\mathrm{f}}=0.7$ and $\mathrm{Ra}=10^{7}$. 


\section{Results for an enclosure with four fins}

The schematic of the system studied here is shown in Fig. 5. The top and bottom walls are insulated, whereas the left and right walls are maintained at temperatures of $T_{h}$ and $T_{c}\left(T_{h}>T_{c}\right)$, respectively. Two fins are placed both at the left and right walls.

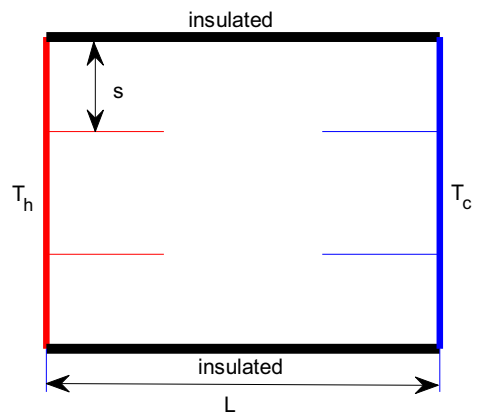

Figure 5. Schematic configuration.

The effects of fin length and spacing are examined for adiabatic (case 1) and highly conductive (thus isothermal at base wall temperature) fins (case 2) similar to [9] who considered a spherical container. Steady or pseudo-steady solution is obtained for $\mathrm{Ra}<10^{6}$. Since the primary interest here is to study unsteady or oscillatory convection, the results only for high $\mathrm{Ra}=7 \times 10^{6}$ are presented and discussed. Figs. 6a, b depict $\mathrm{Nu}$ variation (with heat transfer from fin included) as a function of time for different $1_{f}$ for both cases, at fin locations of $\mathrm{s}=[0.23,0.77]$

which represents a fin placement closer to adiabatic horizontal walls. With insulated fins, heat transfer decreases with fin length, whereas it is enhanced with highly conductive fins for all fin lengths except $\mathrm{l}_{\mathrm{f}}=0.1$. In comparison with case 2 , case 1 yields a more steady behavior with $\mathrm{Nu}$ and a considerably less spread with respect to the fin length. Oscillating $\mathrm{Nu}$ is obtained only for $1_{f}=0.25$ in case 1 , whereas larger oscillations are present for $\mathrm{l}_{\mathrm{f}}=0.25$ and 0.35 for case 2 . Figs. $6 \mathrm{c}, \mathrm{d}$ show $\mathrm{Nu}$ variation for fins placed evenly with $\mathrm{s}=[0.33,0.67]$, exhibiting persistent sinusoidal oscillations particularly for $\mathrm{l}_{\mathrm{f}}=0.35$ in both cases. $\mathrm{Nu}$ oscillations are significant in Figs. $6 \mathrm{~b}, \mathrm{~d}$ for $\mathrm{l}_{\mathrm{f}}=0.25$ and 0.35 , indicating that highly conductive fins cause unsteady convection unless they are short. The comparison of Figs. $6 \mathrm{~b}$ (with $\mathrm{s}=[0.23,0.77]$ ) and $6 \mathrm{~d}$ (with $\mathrm{s}=[0.33,0.67]$ ) reveals higher frequency of oscillations in the former, with the oscillations for $\mathrm{l}_{\mathrm{f}}=0.25$ being regular in the former vs. irregular in the latter. Case 1 is visualized in Fig. 7 in terms of streamlines for three fin lengths $(0.1,0.2$, and 0.35$)$ and two prescribed fin locations at $\mathrm{t}=0.12$. Each configuration has its own specific flow field also manifesting one or more vortices rotating counter-clock wise in the separation regions after the fluid passes the fins. Corresponding temperature field is given in Fig. 8. Case 2 is similarly visualized in Figs. 9 and 10 . Note, particularly for $1_{\mathrm{f}}=0.35$, how different the flow fields are between the two cases in both fin location

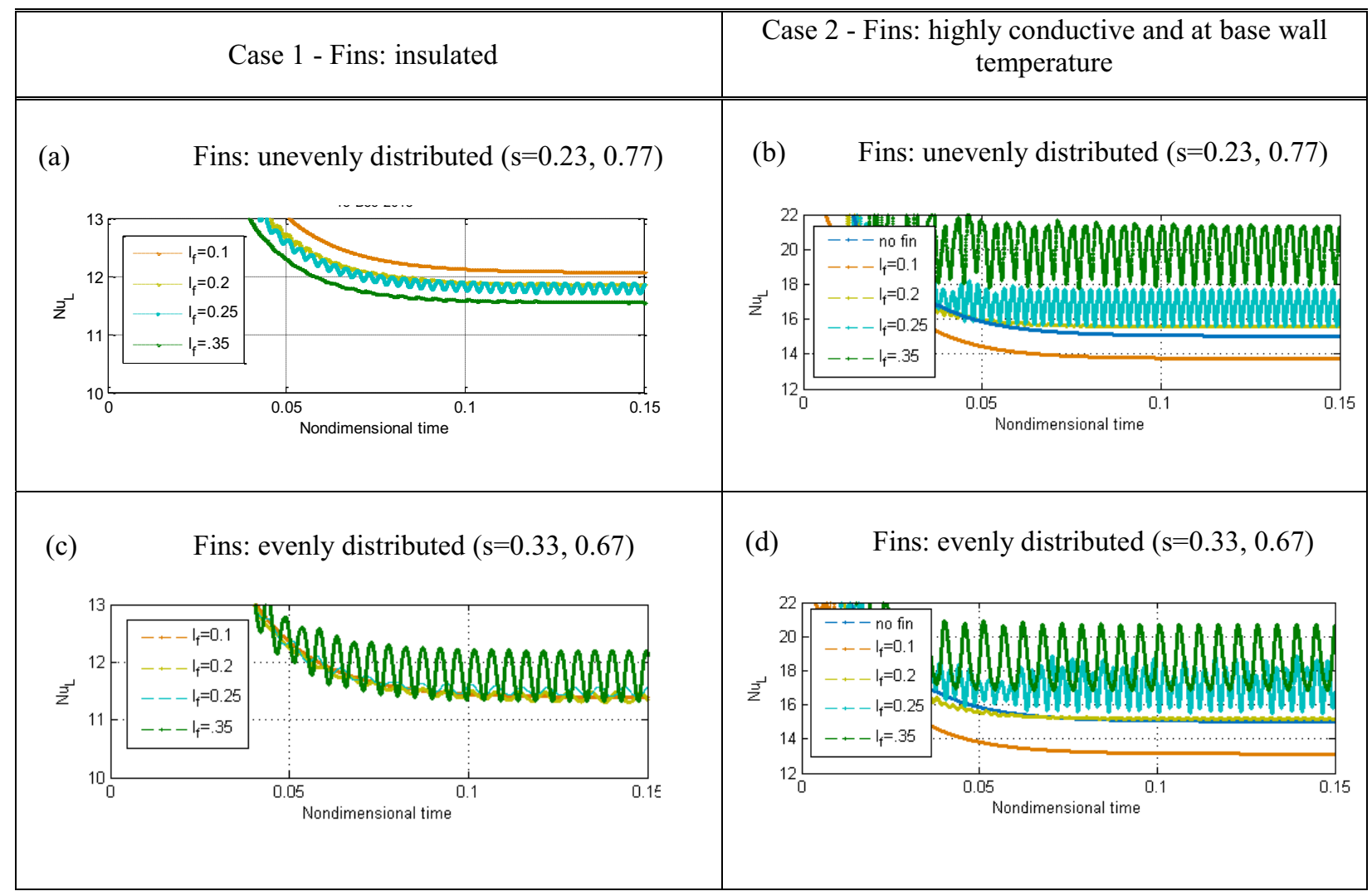

Figure 6. Evolution of $\mathrm{Nu}_{\mathrm{L}}$ for $\mathrm{l}_{\mathrm{f}}=0.1,0.2,0.25$, and 0.35 for $\mathrm{Ra}=7 \times 10^{6}$, left column: fins are insulated, right column: fins are highly conductive and at the base wall temperature $(\mathrm{Nu}=15.07$ for no fin). 


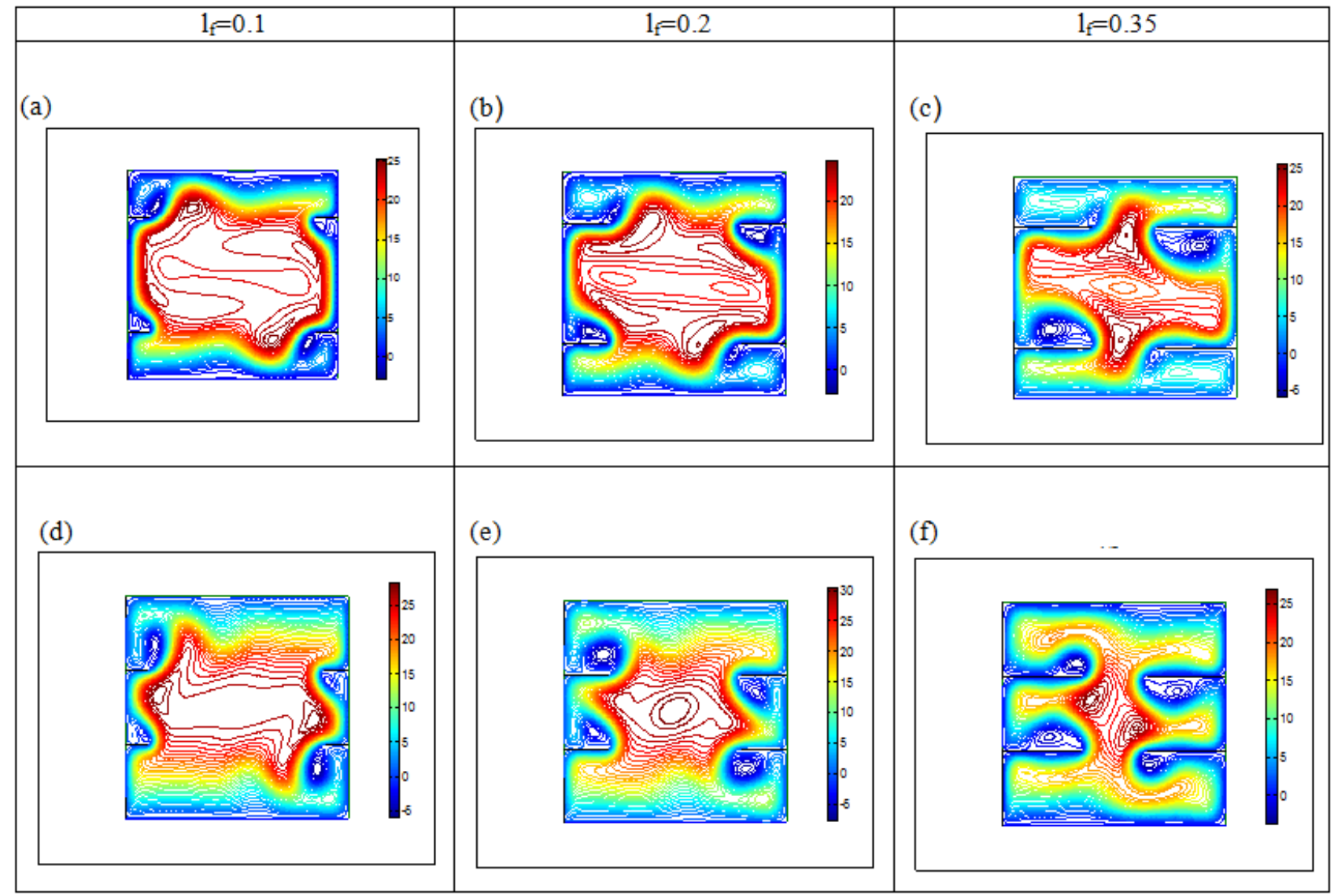

Figure 7. Streamlines for Case 1 (fins are insulated) with $\mathrm{Ra}=7 \times 10^{6}$ and fin lengths of $0.1(\mathrm{a}, \mathrm{d}), 0.2(\mathrm{~b}, \mathrm{e})$, and $0.35(\mathrm{c}, \mathrm{f})$; $\mathrm{s}=[0.23,0.77](\mathrm{a}, \mathrm{b}, \mathrm{c})$ and $\mathrm{s}=[0.33,0.67](\mathrm{d}, \mathrm{e}, \mathrm{f})$.

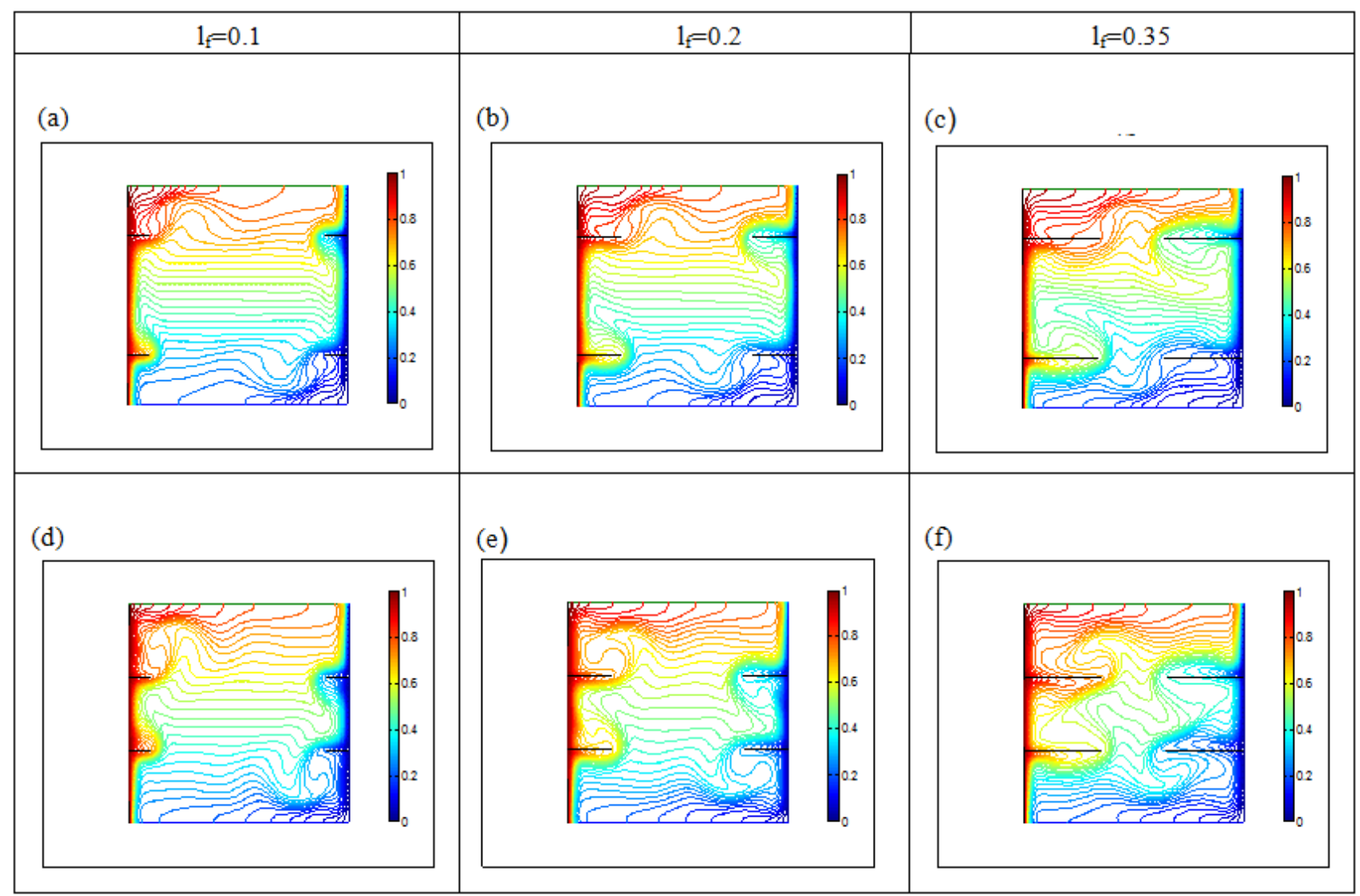

Figure 8. Isotherms for Case 1 (fins are insulated) with $\mathrm{Ra}=7 \times 10^{6}$ and fin lengths of $0.1(\mathrm{a}, \mathrm{d}), 0.2(\mathrm{~b}, \mathrm{e})$, and $0.35(\mathrm{c}, \mathrm{f})$; $\mathrm{s}=[0.23,0.77](\mathrm{a}, \mathrm{b}, \mathrm{c})$ and $\mathrm{s}=[0.33,0.67](\mathrm{d}, \mathrm{e}, \mathrm{f})$. 


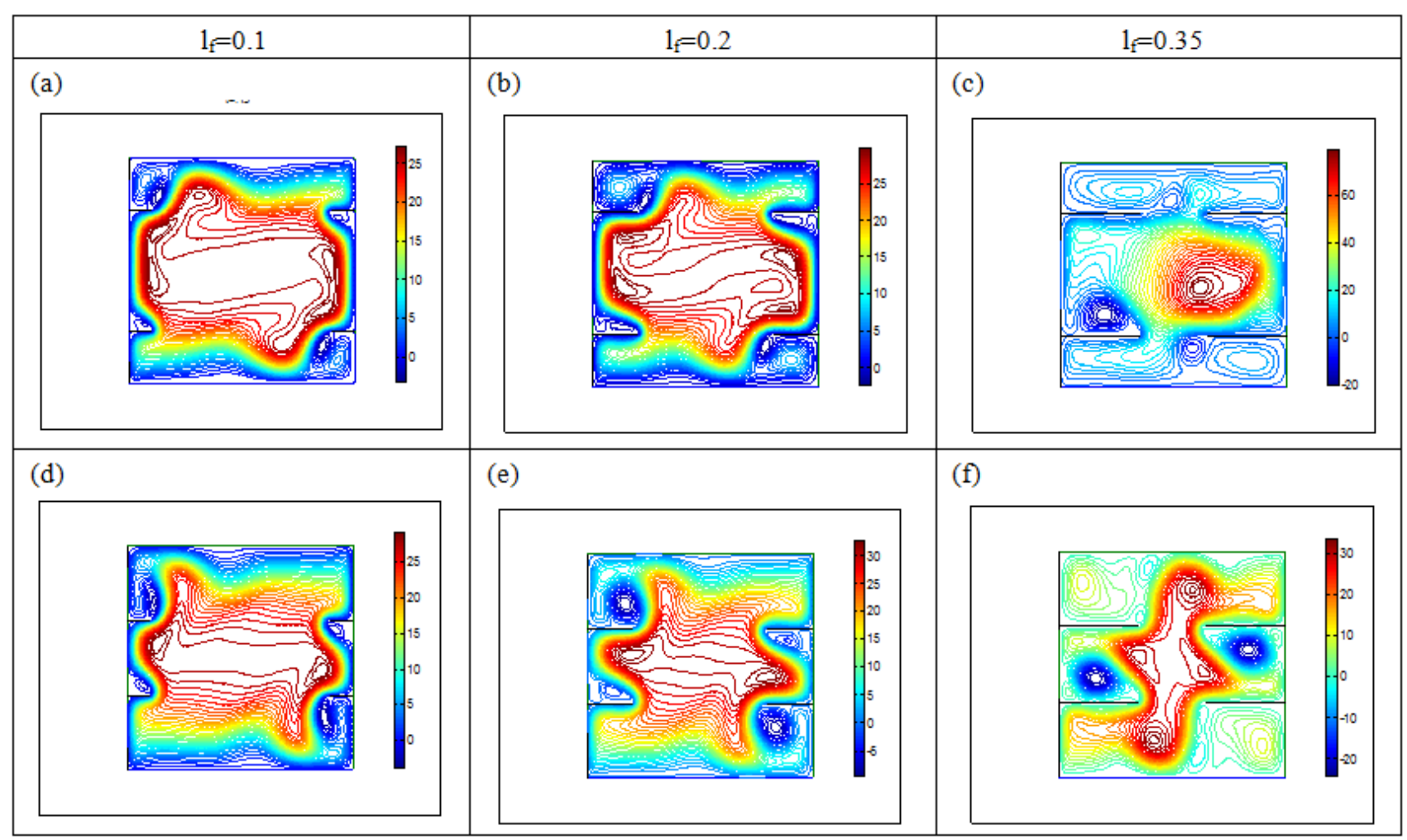

Figure 9. Streamlines for Case 2 (fins are highly conductive and at base wall temperature) with $\mathrm{Ra}=7 \times 10^{6}$ and fin lengths of $0.1(\mathrm{a}, \mathrm{d}), 0.2(\mathrm{~b}, \mathrm{e})$ and $0.35(\mathrm{c}, \mathrm{f}) ; \mathrm{s}=[0.23,0.77](\mathrm{a}, \mathrm{b}, \mathrm{c})$ and $\mathrm{s}=[0.33,0.67](\mathrm{d}, \mathrm{e}, \mathrm{f})$.

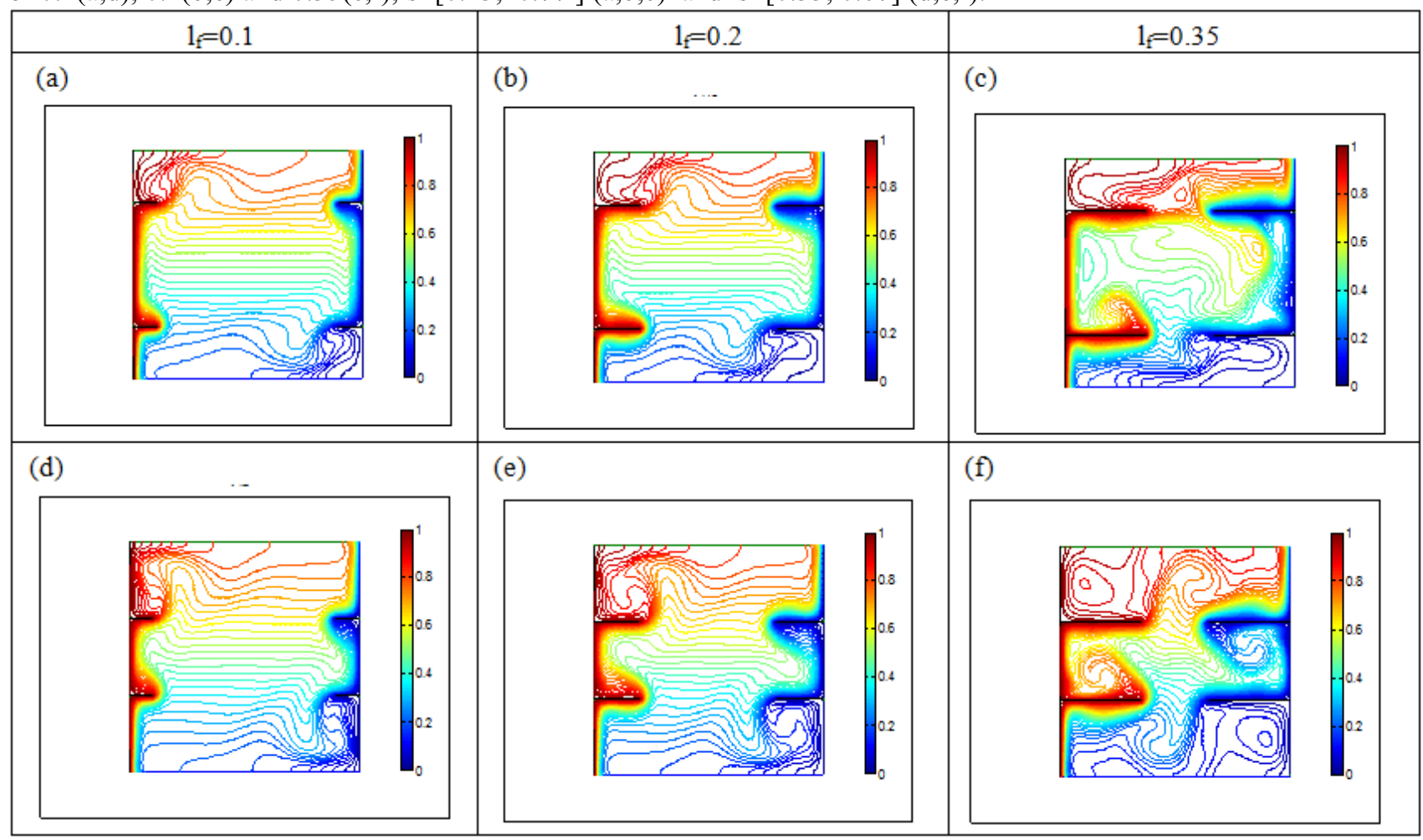

Figure 10. Isotherms for Case 2 (fins are highly conductive and at base wall temperature) with $\mathrm{Ra}=7 \times 10^{6}$ and fin lengths of $0.1(\mathrm{a}, \mathrm{d}), 0.2(\mathrm{~b}, \mathrm{e})$ and $0.35(\mathrm{c}, \mathrm{f}) ; \mathrm{s}=[0.23,0.77](\mathrm{a}, \mathrm{b}, \mathrm{c})$ and $\mathrm{s}=[0.33,0.67](\mathrm{d}, \mathrm{e}, \mathrm{f})$.

\section{Concluding Remarks}

A computational study of laminar natural convection with Boussinesq approximation within a differentially heated square cavity in the presence of thin fins is presented. The suppression and enhancement of heat transfer are examined by considering adiabatic and highly conductive fins at varying lengths and locations. The transitions from steady-state to regular oscillating and from oscillating to chaotic flow occur depending on the location and length 
of fins and Ra. It is important to examine the fin lengths and locations for optimum performance of fins when heat transfer modification is desirable since the dynamic behavior of fluid is greatly influenced by the fin length and spacing.

\section{References}

1. K. H. Winters, Laminar natural convection in a partially divided rectangular cavity at high Rayleigh number, International J. for Numerical Methods in Fluids 8, 247-281 (1988).

2. M. Sathiyamoorthy and Ali J. Chamkha, Analysis of natural convection in a square cavity with a thin partition for linearly heated side walls, International J. Numerical Methods for Heat and Fluid Flow 24, 5, 1067-1072 (2014).

3. G. N. Faces, Natural convection in a cavity with fins attached to both vertical walls, J. Thermophysics and Heat Transfer 7, 4, 555-560 (1993).

4. A. Nag, A. Sarkar and V. M. K. Sastri, Natural Convection in a differentially heated square cavity with a horizontal partition plate on the hot wall,
Computer Methods in Applied Mechanics and Engineering 110, 143-156 (1993).

5. X. Shi and J. M. Khodadadi, Laminar natural convection heat transfer in a differentially heated square cavity due to a thin fin on the hot wall, Transactions of ASME 125, 624-634 (2003).

6. E. Bilgen, Natural convection in cavities with a thin fin on the hot wall, International $J$. Heat and Mass Transfer 48, 3493-3505 (2005).

7. S. A. Nada, Natural convection heat transfer in horizontal and vertical closed narrow enclosures with heated rectangular finned base plate, International $J$. Heat and Mass Transfer 50, 667-679 (2007).

8. E. Evren-Selamet, V.S. Arpaci, and C. Borgnakke: Simulation of laminar buoyancy-driven flows in an enclosure, Numerical Heat Transfer, Part A, 22, 401420 (1992).

9. Y. Duan, S. F. Hosseinizadeh, J. M. Khodadadi, Effects of insulated and isothermal baffles on pseudosteady-state natural convection inside spherical containers, J. Heat Transfer 132, 6, 1-10 (2010). 